\title{
The Improvement Effect of Dispersant in Fluorite Flotation: Determination by the Analysis of XRD and FESEM-EDX
}

\author{
Y. J. Li, ${ }^{1}$ F. Y. Sun, ${ }^{1}$ Y. Zhou, ${ }^{1}$ and L. Zeng ${ }^{2}$ \\ ${ }^{1}$ College of Earth Sciences, Jilin University, Changchun 130000, China \\ ${ }^{2}$ College of Materials Science and Engineering, Chongqing University, Chongqing 400030, China \\ Correspondence should be addressed to L. Zeng; zool@foxmail.com
}

Received 29 July 2014; Accepted 26 August 2014

Academic Editor: Wen Zeng

Copyright (c) 2015 Y. J. Li et al. This is an open access article distributed under the Creative Commons Attribution License, which permits unrestricted use, distribution, and reproduction in any medium, provided the original work is properly cited.

\begin{abstract}
Different dispersants were added in the dispersion process to improve the efficiency of fluorite flotation. The types and dosage of dispersant on the improvement of fluorite flotation were investigated; when the sodium polyacrylate (SPA) was used as the dispersant and its addition is $0.5 \%$, the concentrate grade of $\mathrm{CaF}_{2}$ increased from $90 \%$ to $98 \%$ and the fluorite recovery increased from $81 \%$ to $85 \%$. Methods of X-ray powder diffraction (XRD), field emission scanning electron microscopy (FESEM), and Energy dispersive X-ray spectrometer (EDX) were used to characterize the sample. According to the analysis of results, the optimal sample consisted of $\mathrm{CaF}_{2}$ and very little $\mathrm{CaCO}_{3}$ in the size range of $0-5 \mu \mathrm{m}$. It could be concluded that the mechanism of improvement for the concentrate grade and recovery of $\mathrm{CaF}_{2}$ was attributed to the change of potential energy barrier which caused the separation of particles with different charge. All results indicate that SPA has a great potential to be an efficient and cost-effective dispersant for the improvement of fluorite flotation.
\end{abstract}

\section{Introduction}

Fluorite, which is a kind of mineral with the highest level of fluoride content, derives its name from the Latin word "flurum." The main chemical component of fluorite is $\mathrm{CaF}_{2}$, and fluorite also contains traces of impurity elements such as silicon, aluminum, magnesium, strontium, yttrium, cerium, and uranium and other foreign matters like asphalt, ferric oxide, and so forth [1]. Fluorite is a kind of equiaxial crystal, often featuring in a cube and octahedron, and it also shapes into a monocrystalline of rhombic dodecahedron or irregular granular aggregate. Fluorite is characterized by the vitreous luster, crispness, shell-shaped fractures, and complete cleavages along the octahedron. With its relative density of 3.18 and melting point of $1360^{\circ} \mathrm{C}$, it is insoluble in water or acid [2]. It has been a long time since humans began to make use of fluorite. Early in the 15th century, Agricola found the features of "Flares" in fluorites and employed them as a metallurgical flux [3]. Fluorite is the most important industrial mineral containing fluorine. It not only is widely used in the industrial sectors such as metallurgy, chemicals, ceramics, building materials, machinery, electrical machinery, aviation, agriculture, medicine, and precise instruments, but also serves as the important energetic materials in the cutting-edge science and emerging industries such as atomic energy, the rockets, and aerospace. Fluorite ore can produce products of different specifications through mineral processing [4]. With the development of industrial technology, there is a growing demand for high-quality fluorite ore (with the contents of $\mathrm{CaF}_{2}$ more than 93\%) [5]. However, there is less rich ore and poorer ore in terms of the fluorite ore resources in China, with the contents of $\mathrm{CaF}_{2}$ in fluorite ore about 35 to $40 \%$ on average [6]. Therefore, we must adopt efficient mineral processing ways so as to improve the contents of $\mathrm{CaF}_{2}$.

At present, we commonly adopt the flotation method to remove the mineral impurities except fluorite in the fluorite ore to improve the content of $\mathrm{CaF}_{2}$, among which the dispersion process is a very important technique and the selection of dispersants will have a direct impact on the contents of $\mathrm{CaF}_{2}$ of the final products [7]. In this work, we chose four types of dispersants, studying the dispersion effect of them on the fluorite purification to produce a high-grade 
TABLE 1: The effect of dispersants on the concentrate grade and recovery of $\mathrm{CaF}_{2}$.

\begin{tabular}{lccc}
\hline Samples & Dispersant & Grade (\%) & Recovery (\%) \\
\hline FR & - & 90 & 81 \\
FSS & SS & 92 & 82 \\
FPAM & PAM & 95 & 82 \\
FHPMC & HPMC & 92 & 83 \\
FSPA & SPA & 98 & 85 \\
\hline
\end{tabular}

concentrate of fluorite. The objective of this study is to explore the best dispersant in increasing the concentrate grade and recovery of $\mathrm{CaF}_{2}$.

\section{Experimental}

2.1. Materials. The fluorite ore used in this work was mined from Inner Mongolia, which mainly consists of $77.12 \% \mathrm{CaF}_{2}$, $11.35 \% \mathrm{CaCO}_{3}, 9.71 \% \mathrm{SiO}_{2}$, and a little clay. The sample was dried at $95^{\circ} \mathrm{C}$ to constant mass and then milled to less than $45 \mu \mathrm{m}$. The dispersants supplied from Aladdin Co. Ltd. are all analytical reagents, including silica sol (SS), polyacrylamide (PAM), hydroxypropyl methyl cellulose (HPMC), and sodium polyacrylate (SPA), and the corresponding samples with different dispersants are FSS, FPAM, FHPMC, and FSPA, respectively.

2.2. Experimental Methods. For the preparation of highgrade fluorite concentrate, the slurry with $200 \mathrm{~g}$ fluorite ore and $700 \mathrm{~mL}$ water was ground in a ball mill for $20 \mathrm{~min}$ while the dispersant was added in this dispersion process, and then, by the process of rougher flotation and cleaner flotation, the final fluorite concentrate was obtained. The fluorite concentrate was dried at $95^{\circ} \mathrm{C}$ to constant mass and weighed, of which the composition was analyzed. From the procedure, the concentrate grade and recovery of fluorite were calculated to choose the best dispersant in increasing the concentrate grade and recovery. The sample prepared with the best dispersant was characterized by different methods, including $\mathrm{X}$-ray powder diffraction (XRD), field emission scanning electron microscopy (FESEM), and energy dispersive Xray spectrometer (EDX). XRD was performed on a Rigaku $\mathrm{D} /$ max-3Bx diffractometer with $\mathrm{Cu} \mathrm{K} \alpha$ radiation, in the range of $30^{\circ}-65^{\circ} 2 \theta$ and at a step size of $0.02^{\circ}$. FESEM micrographs were performed by the Hitachi SU8010 operating at the accelerating voltage of $15 \mathrm{kV}$ and FESEM images were taken at different magnifications. The instrument was equipped with the energy dispersion X-ray spectroscopy.

\section{Results and Discussion}

3.1. Effects of Dispersants. Table 1 shows the effect of dispersants ( $0.5 \%$ addition) on the concentrate grade and recovery of $\mathrm{CaF}_{2}$. As can be seen from Table 1, without the addition of dispersant, the concentrate grade and recovery of $\mathrm{CaF}_{2}$ were $90 \%$ and $81 \%$, and, with the addition of dispersant, it could increase the concentrate grade and recovery of $\mathrm{CaF}_{2}$

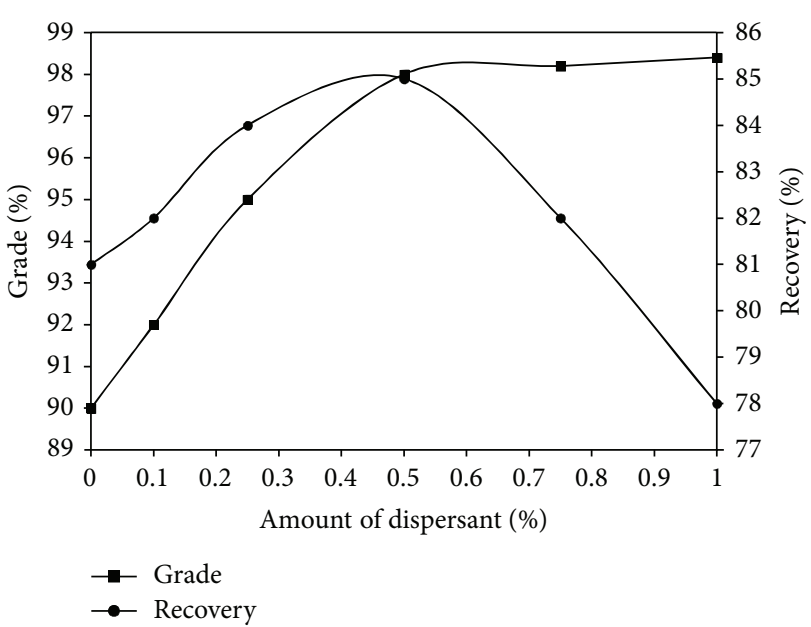

FIGURE 1: The effect of SPA amount on the concentrate grade and recovery of $\mathrm{CaF}_{2}$.

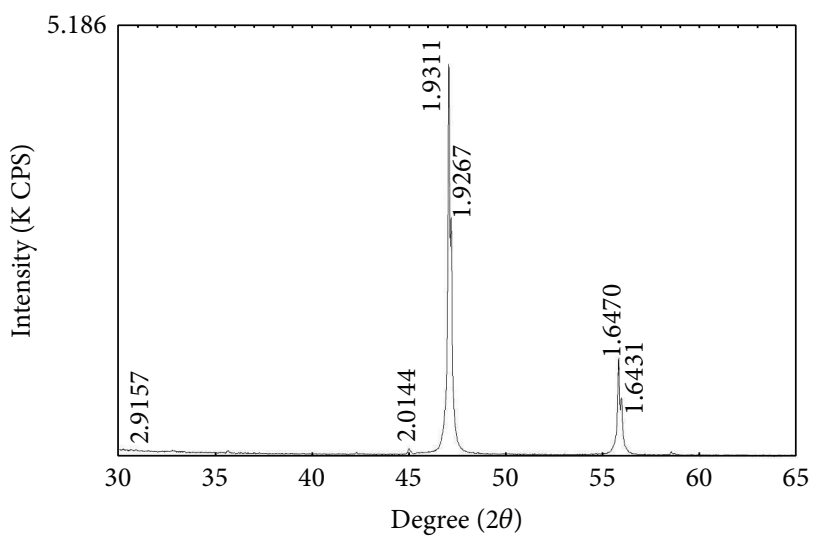

FIGURE 2: XRD pattern of FSPA.

but with a different effect. The concentrate grade of $\mathrm{CaF}_{2}$ was in the range of 92 98\% and the recovery was in the range of $82 \sim 85 \%$ with the addition of dispersant. In particular, with the addition of SPA, the concentrate grade and recovery of FSPA were $98 \%$ and $85 \%$, which increased about $8 \%$ and $4 \%$ compared with FR. It can be attributed to the dispersion effect which dispersed the mineral particles equably in the solution and thus prevented other minerals such as calcite and quartz from being entered into the concentrate [8]. Hence, the addition of dispersant has great influences on the concentrate grade and recovery of $\mathrm{CaF}_{2}$.

3.2. The Effect of Dispersant Amount. The amount of dispersant is an important parameter determining the concentrate to grade and recovery of $\mathrm{CaF}_{2}$. The effect of SPA amount on the concentrate grade and recovery is shown in Figure 1, which indicates that the dispersant amount has great influence on both of concentrate grade and recovery. It is observed that the concentrate grade of $\mathrm{CaF}_{2}$ increases obviously with the increase of SPA addition all the while, and the increases are much stronger in the low SPA addition than in the high 

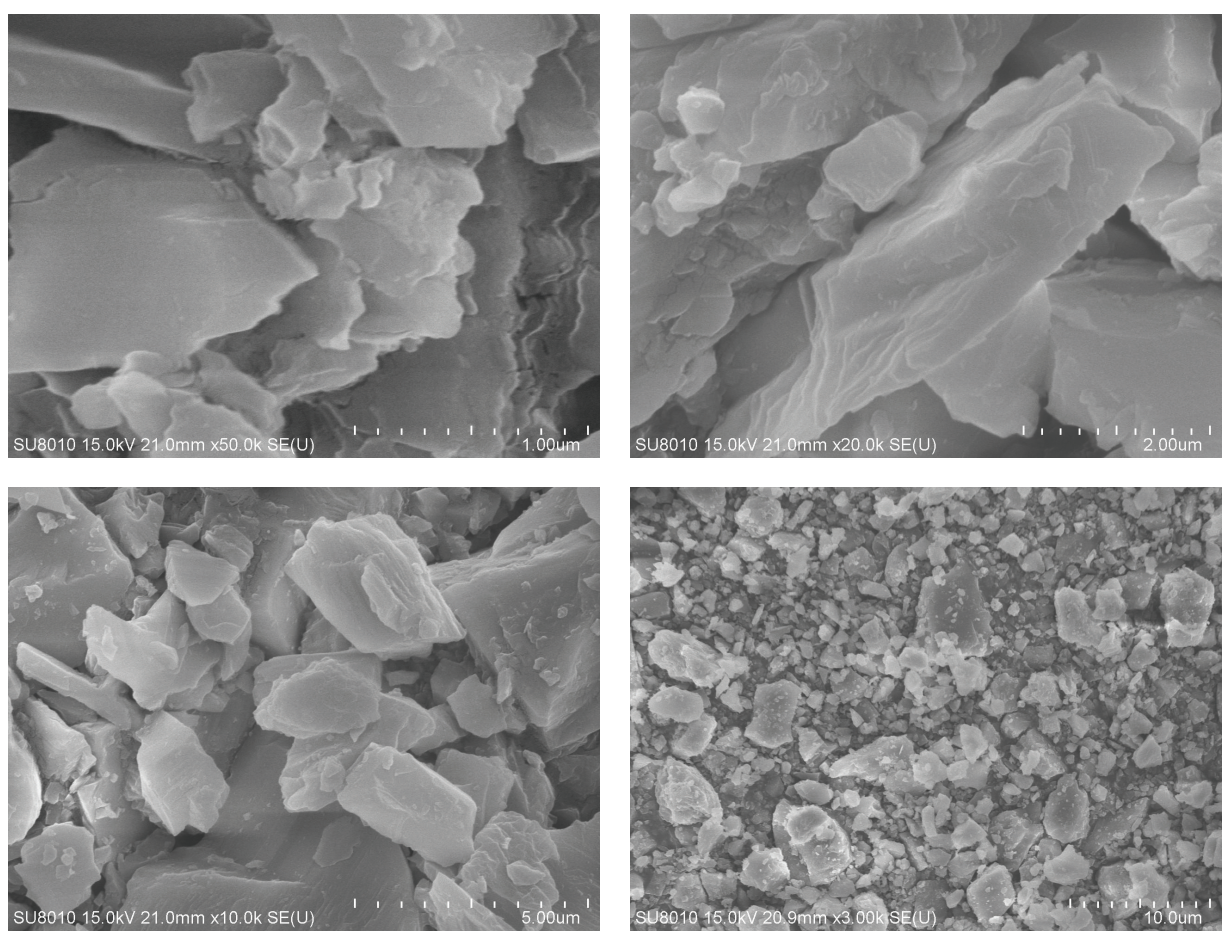

FIGURE 3: FESEM micrographs of FSPA.
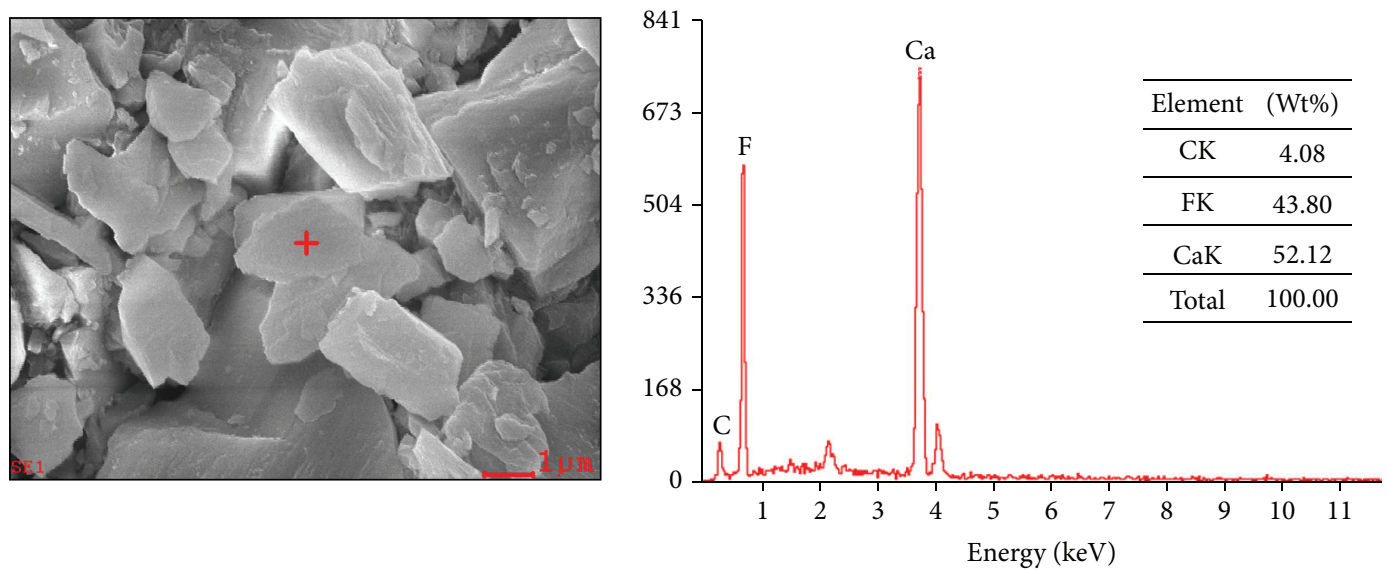

FIGURE 4: FESEM-EDX analysis of FSPA.

addition, which can be attributed to the dispersion effect [9]. As the dispersibility of raw ore is poor, the impurity is hard to separate. With the addition of SPA, the dispersibility is improved and causes the increase of concentrate grade. However, the recovery of $\mathrm{CaF}_{2}$ increases with the increase of dispersant at first but reaches the maximum value when the dispersant addition is $0.5 \%$ and then declines. It shows that too much dispersant addition makes a bad effect on the recovery of $\mathrm{CaF}_{2}$ and the best amount of SPA addition is about $0.5 \%$.

3.3. XRD Characterization. XRD pattern reveals the microstruc-ture and composition of sample. The XRD pattern of FSPA is presented in Figure 2. As can be seen, the FSPA consists of fluorite $\left(\mathrm{CaF}_{2}\right)$ with peaks at 1.9311, 1.9267, 1.6470, and $1.6431 \AA$ (corresponding to $46.1,47.2,55.7$, and $56.3^{\circ} 2 \theta$, resp.). The peaks are strong and sharp, reflecting an ordered and high-crystallinity structure, which show that the disposal of floatation does not change the crystallinity structure of fluorite $[10,11]$. Meanwhile, the peaks of calcite, quartz, and other minerals are almost not observed, which indicate the high concentrate grade of $\mathrm{CaF}_{2}$. As already introduced, fluorite, calcite, and quartz are the main minerals in the fluorite ore; the result suggests that, with the SPA addition, the other minerals such as calcite and quartz can be removed drastically from the concentrate and a high concentrate grade of $\mathrm{CaF}_{2}$ can be obtained. 
3.4. FESEM-EDX Characterization. The FESEM micrographs of FSPA are presented in Figure 3. As it can be seen in Figure 3, the microappearance of FSPA is irregular platelet and pile on each other, and its size is in the range of $0-5 \mu \mathrm{m}$, and its appearance is consistent with the typical characteristics of fluorite [12]. The particle size of FSPA is very fine due to the addition of dispersant, which is beneficial for the floatation. As the main minerals in the fluorite ore are fluorite, calcite, and quartz which have their isoelectric point (IEP) at different $\mathrm{pH}$, the addition of dispersant changes the $\mathrm{pH}$ of slurry and endows the minerals with different charges, which are beneficial for the separation of the minerals and getting the high concentrate grade of $\mathrm{CaF}_{2}[13,14]$. It can be explained that the existence of potential energy barrier between particles keeps from the approach of particles, which causes the aggregative stability of colloidal suspensions, but the interaction energies of electrical double layer and van der Waals cause the potential energy barrier to arise and the particles with different charge to separate [15-17]. Meanwhile, the sample was characterized by the method of EDX in order to analyze the composition of the sample. Figure 4 shows the results of FESEM-EDX analysis of FSPA. As it can be seen in Figure 4, the EDX spectra reveal the presence of calcium, fluorine, and carbon $(\mathrm{Ca}=52.12 \mathrm{wt} \%, \mathrm{~F}=43.80 \mathrm{wt} \%$, and $\mathrm{C}=$ $4.08 \mathrm{wt} \%)$, which indicate that the sample consists of $\mathrm{CaF}_{2}$, and little of $\mathrm{CaCO}_{3}$ may be residual [18]. In addition, $\mathrm{Si}$ is not detected in the sample which suggests the quartz had been removed completely. The result shows the high concentrate grade of $\mathrm{CaF}_{2}$, and in this system the quartz, compared with calcite, is easier to be removed with the addition of dispersant.

\section{Conclusion}

The final results presented in this paper demonstrated the influence of dispersants in the floatation of fluorite. It was shown that all the dispersants exhibited certain effects in increasing the concentrate grade and recovery of $\mathrm{CaF}_{2}$ and SPA presented high improvement in the purification of fluorite ores by flotation. With the addition of SPA in the slurry, the sample with high concentrate grade and recovery of $\mathrm{CaF}_{2}$ was prepared, and when the addition of SPA is $0.5 \%$, FSPA obtained the highest concentrate grade (98\%) and recovery (85\%). FSPA were characterized by several methods, including XRD, FESEM, and EDX. According to the analysis of results, the optimal sample consisted of $\mathrm{CaF}_{2}$ and very little $\mathrm{CaCO}_{3}$ in the size range of $0-5 \mu \mathrm{m}$. It can be concluded that the mechanism of improvement for the concentrate grade and recovery of $\mathrm{CaF}_{2}$ could be attributed to the change of potential energy barrier which caused the separation of particles with different charges.

Generally speaking, in the practical application, the addition of dispersant is technically and economically reliable for the floatation of fluorite, including (a) the high concentrate grade of $\mathrm{CaF}_{2}$, (b) the increasing recovery of ore fluorite, and (c) the finer particles. Meanwhile, the addition of dispersant is cost-effective and has a high recovery for $\mathrm{CaF}_{2}$ from the slurry. Furthermore, the dispersion disposal with SPA as the dispersant in the fluorite flotation could increase the concentrate grade from $90 \%$ to $98 \%$ while the fluorite recovery was increased from $81 \%$ to $85 \%$. Hence, in order to increase the concentrate grade and recovery of $\mathrm{CaF}_{2}$, the SPA can be used as the potential dispersant in the fluorite flotation.

\section{Conflict of Interests}

The authors declare no conflict of interests regarding the publication of this paper.

\section{Acknowledgments}

The study was supported by the Research Funds for the Comprehensive Test Technology: The Mineralization Elements and Components of Associated Fluorite (12120113014300). The authors are also grateful for the support of Siziwang Banner Land and Resources Bureau.

\section{References}

[1] J. S. Laskowski and R. J. Pugh, "Dispersions stability and dispersing agents," in Colloid Chemistry in Mineral Processing, J. S. Laskowski and J. Ralston, Eds., pp. 151-166, Elsevier, Amsterdam, The Netherlands, 1992.

[2] M. A. Elrashidi and W. L. Lindsay, "Chemical equilibria of fluorine in soils: a theoretical development.," Soil Science, vol. 141, no. 4, pp. 274-280, 1986.

[3] C. E. Manning and D. K. Bird, "Fluorian garnets from the host rocks of the Skaergaard intrusion: implications for metamorphic fluid composition," American Mineralogist, vol. 75, no. 7-8, pp. 859-873, 1990.

[4] G. Bhaskar Raju and S. Prabhakar, "Beneficiation of fluorspar by column flotation," Minerals and Metallurgical Processing, vol. 17, no. 3, pp. 167-172, 2000.

[5] G. Ateşok, F. Boylu, and M. S. Çelik, "Carrier flotation for desulfurization and deashing of difficult-to-float coals," Minerals Engineering, vol. 14, no. 6, pp. 661-670, 2001.

[6] X. Zhou, J. Liu, Y. Wang, D. Tao, and C. Zhao, "Pilot-scale study of fluorite beneficiation using a cyclonic static microbubble flotation column," Minerals and Metallurgical Processing, vol. 24, no. 4, pp. 271-274, 2007.

[7] S. Song, A. Lopez-Valdivieso, C. Martinez-Martinez, and R. Torres-Armenta, "Improving fluorite flotation from ores by dispersion processing," Minerals Engineering, vol. 19, no. 9, pp. 912-917, 2006.

[8] R. A. Grau, J. S. Laskowski, and K. Heiskanen, "Effect of frothers on bubble size," International Journal of Mineral Processing, vol. 76, no. 4, pp. 225-233, 2005.

[9] R. P. Garibay, P. M. Gallegos, S. A. Uribe, and A. F. Nava, "Effect of collection zone height and operating variables on recovery of overload flotation columns," Minerals Engineering, vol. 15, no. 5, pp. 325-331, 2002.

[10] L. A. Kienko and O. V. Voronova, "Performance evaluation of comprehensive processing of zinc-fluorite ore in the Voznesensky mining area," Journal of Mining Science, vol. 48, no. 5, pp. 928-933, 2012.

[11] W. Aliaga, C. H. Sampaio, I. A. S. Brum, K. R. S. Ferreira, and M. A. Batistella, "Flotation of high-grade fluorite in a short column under negative bias regime," Minerals Engineering, vol. 19, no. 13, pp. 1393-1396, 2006. 
[12] J. Zawala, J. Drzymala, and K. Malysa, "An investigation into the mechanism of the three-phase contact formation at fluorite surface by colliding bubble," International Journal of Mineral Processing, vol. 88, no. 3-4, pp. 72-79, 2008.

[13] J. D. Miller, K. Fa, J. V. Calara, and V. K. Paruchuri, “The surface charge of fluorite in the absence of surface carbonation," Colloids and Surfaces A: Physicochemical and Engineering Aspects, vol. 238, no. 1-3, pp. 91-97, 2004.

[14] Z. Xu, J. Liu, J. W. Choung, and Z. Zhou, "Electrokinetic study of clay interactions with coal in flotation," International Journal of Mineral Processing, vol. 68, no. 1-4, pp. 183-196, 2003.

[15] Q. Wang, "A study on shear coagulation and heterocoagulation," Journal of Colloid And Interface Science, vol. 150, no. 2, pp. 418427, 1992.

[16] Y. Zhang and S. Song, "Beneficiation of fluorite by flotation in a new chemical scheme," Minerals Engineering, vol. 16, no. 7, pp. 597-600, 2003.

[17] A. A. Abramov and D. V. Magazanik, “Theoretical basis for optimal collector concentrations and pulp $\mathrm{pH}$ values during flotation of sulfide-free minerals," Journal of Mining Science, vol. 42, no. 2, pp. 178-188, 2006.

[18] W. Zhou, J. Moreno, R. Torres, H. Valle, and S. Song, "Flotation of fluorite from ores by using acidized water glass as depressant," Minerals Engineering, vol. 45, pp. 142-145, 2013. 

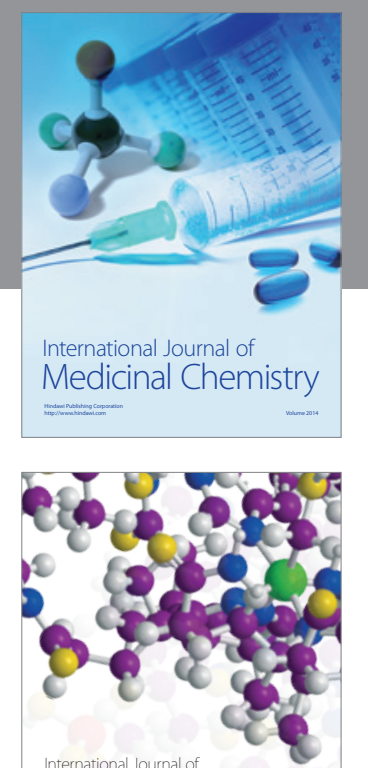

\section{Carbohydrate} Chemistry

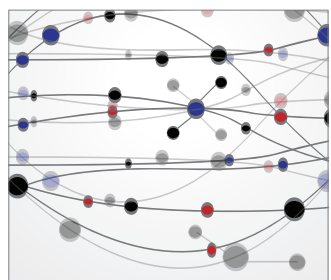

The Scientific World Journal
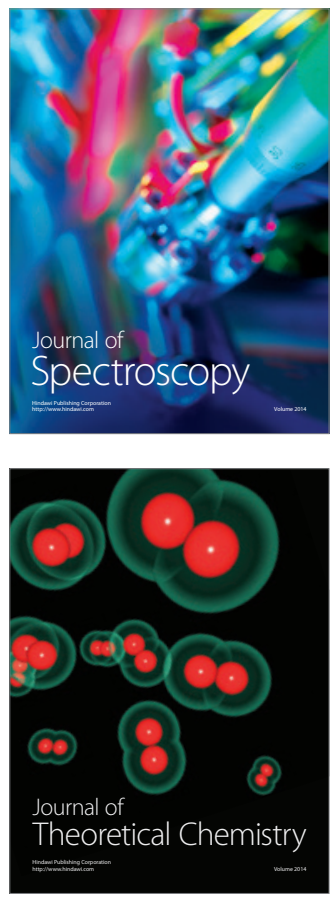
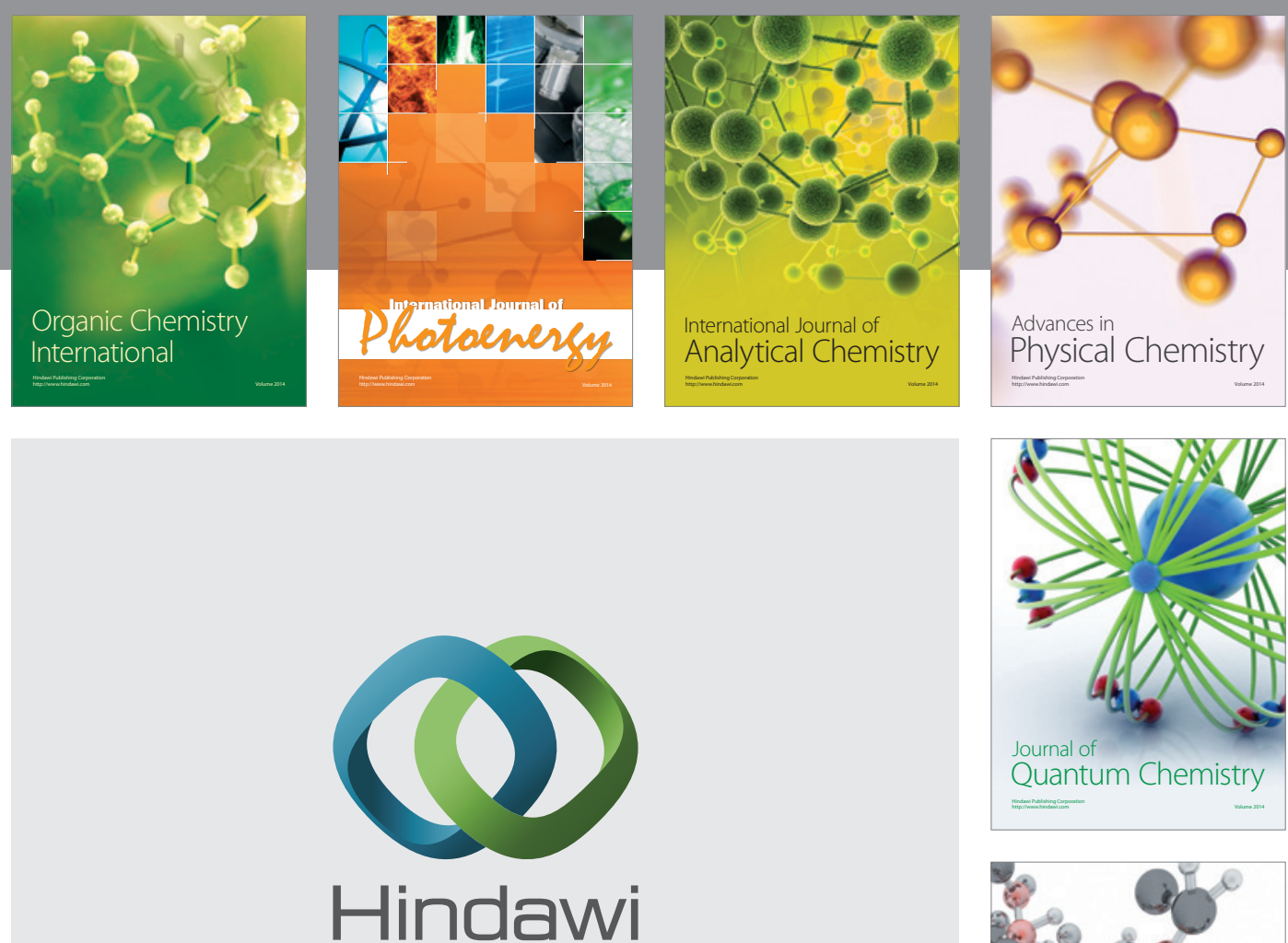

Submit your manuscripts at

http://www.hindawi.com

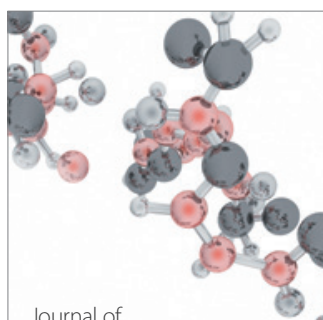

Analytical Methods

in Chemistry

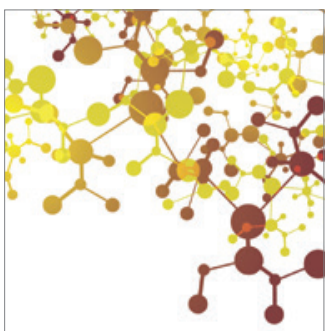

Journal of

Applied Chemistry

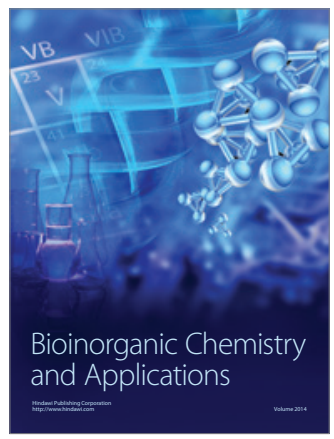

Inorganic Chemistry
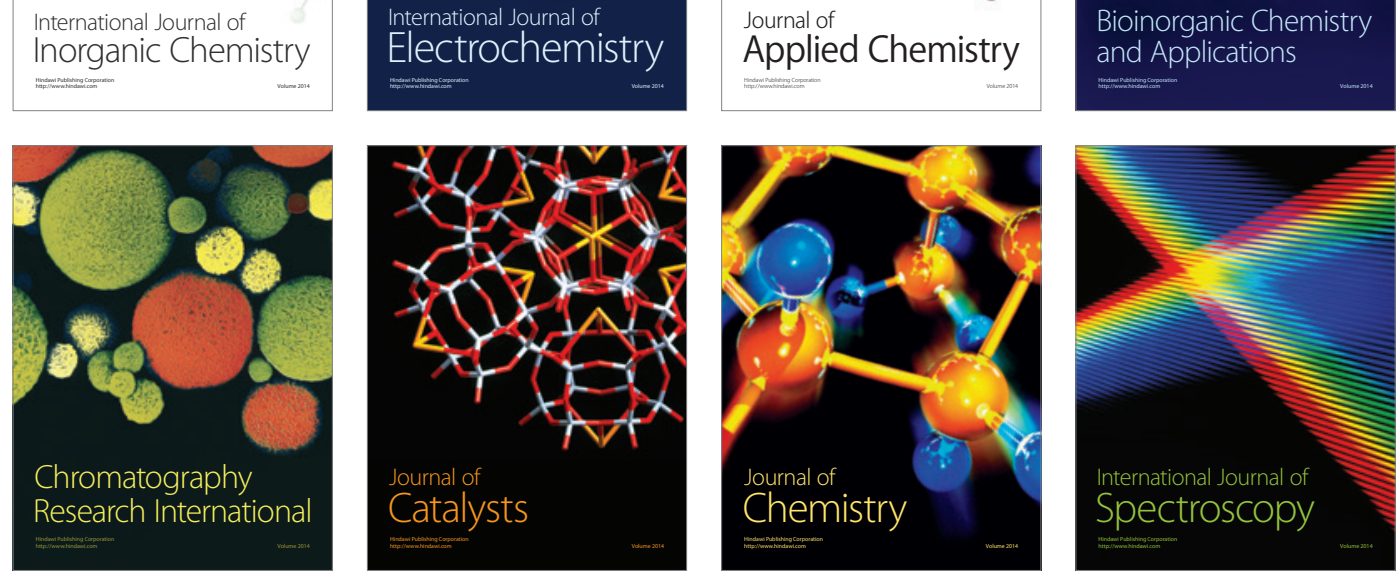